\title{
Advances and Challenging Issues in Subsurface Drainage Module Technology and BIOECODS: A Review
}

\author{
Abdurrasheed Sa'id Abdurrasheed ${ }^{1,2 *}$, Khamaruzaman Wan Yusof ${ }^{1}$, Husna Bt Takaijudin ${ }^{1}$, \\ Aminuddin Ab. Ghani ${ }^{3}$, Muhammad Mujahid Muhammad ${ }^{4}$, and Abdulkadir Taofeeq \\ Sholagberu ${ }^{1,5}$ \\ ${ }^{1}$ Department of Civil and Environmental Engineering, Universiti Teknologi Petronas, \\ Bandar Seri Iskandar, Perak, Malaysia \\ ${ }^{2}$ Department of Civil Engineering, Ahmadu Bello University, Zaria, Nigeria \\ ${ }^{3}$ River Engineering and Urban Drainage Research Centre (REDAC), Engineering Campus, Universiti \\ Sains Malaysia, Nibong Tebal, Pulau Pinang, Malaysia \\ ${ }^{4}$ Department of Water Resources and Environmental Engineering, Ahmadu Bello University, Zaria, \\ Nigeria \\ ${ }^{5}$ Department of Water and Environmental Engineering, University of Ilorin, Ilorin Nigeria
}

\begin{abstract}
Subsurface drainage modules are important components of the Bio-ecological Drainage System (BIOECODS) which is a system designed to manage stormwater quantity and quality using constructed grass swales, subsurface modules, dry and wet ponds. BIOECODS is gradually gaining attention as one of the most ecologically sustainable solutions to the frequent flash floods in Malaysia and the rest of the world with a focus on the impact of the subsurface modules to the effectiveness of the system. Nearly two decades of post-construction research in the BIOECODS technology, there is need to review findings and areas of improvement in the system. Thus, this study highlighted the key advances and challenges in these subsurface drainage modules through an extensive review of related literature. From the study, more work is required on the hydraulic characteristics, flow attenuation and direct validation methods between field, laboratory, and numerical data. Also, there is concern over the loss of efficiency during the design life especially the infiltration capacity of the module, the state of the geotextile and hydronet over time. It is recommended for the sake of higher performance, that there should be an onsite methodology to assess the permeability, rate of clogging and condition of the geotextile as well as the hydronet over time.
\end{abstract}

\section{Introduction}

Urban drainage is continuously overloaded with surface runoff as urbanization increases resulting in receiving water pollution and frequent flood events which are major challenges

*Corresponding e-mail: asabdurrasheed@,abu.edu.ng 
resulting in receiving water pollution and frequent flood events which are major challenges to both humans and aquatic animals [1-3]. Researchers have shown that attempts to re-design or upgrade the existing systems failed to solve the problem as it does not act directly on the courses. Thus, necessitating the need to develop stormwater management control and reduction strategies. These strategies involve promoting infiltration, detention, retention with the aim of reducing stormwater runoff [4]. The entire philosophy is to maintain the hydrological water balance as close to pre-development conditions as possible. These strategies termed stormwater best management practice (BMP) $[5,6]$ and the resulting drainage system is referred to as sustainable drainage systems (SUDs) [5] or sometimes called low impact development (LID) [7, 8].

Management of stormwater has been transformed from the traditional method of quick runoff removal to sustainable management approaches by employing various control measures. These measures are strongly dependent on the location where the controls are implemented and can be classified into three including "source control", collection system controls and "quantity and quality controls" [6,9]. Urbanization will always increase the quantity of stormwater runoff in a catchment as a result of an increase in the proportion of impervious surfaces such as pavement and roofs [10]. Among the requirements of runoff quantity control (Flood mitigation) is post-development peak flow must be equal to or less than the pre-development peak flow [11]. Urban development in Malaysia over the last three decades has resulted in dramatic hydrological changes which include alterations in the natural hydrology and infiltration characteristics of the previously rural catchments. This has resulted to problems such as increase in stormwater flow, flood peaks, water pollution by transporting pollutants, scouring of channels, sedimentation, etc $[12,13]$. The Department of Irrigation and Drainage (DID) Malaysia has provided a new approach which involved the use of "control at source" (i.e., dealing with runoff as at when and where the storm event occurs) and BMP which adopts the use of various quality and quantity control methods to achieve minimal or zero impact in any development $[14,15]$.

Drainage Modules or storage tank modules are rainwater harvesting systems mostly used as sub-surface storage units to promote reuse, infiltration, quantity, and quality improvement of surface water [16]. River Engineering and Urban Drainage Research Centre (REDAC) has tested modules of different structures and patterns as in Fig. 1. Two of these modules had been applied as a pilot study in the Bio-ecological Drainage System (BIOECODS) of Universiti Sains Malaysia (USM) Engineering campus, and Taiping Health Clinic, Malaysia. The others two are the REDAC module and the commercial Rainsmart module. The BIOECODS is designed based on the "control at source" concept. They are substitutes to the traditional hard concrete channel systems designed to manage stormwater quantity and quality through the use of constructed grass swales, subsurface modules, dry and wet ponds $[14,17]$. These drainage modules provide flow attenuations in the BIOECODS and ensure eco-friendly drainage systems that will be more erosion resistant which can allow natural infiltration [16]. They are now being used and promoted as means of controlling floods, especially in the BIOECODS technology. The findings and areas of improvement especially on performance evaluation methods, their role in water quality and quantity control is gradually increasing. This study, therefore, highlights the key advances and challenging issues in these subsurface drainage modules through an extensive review of related literature. 


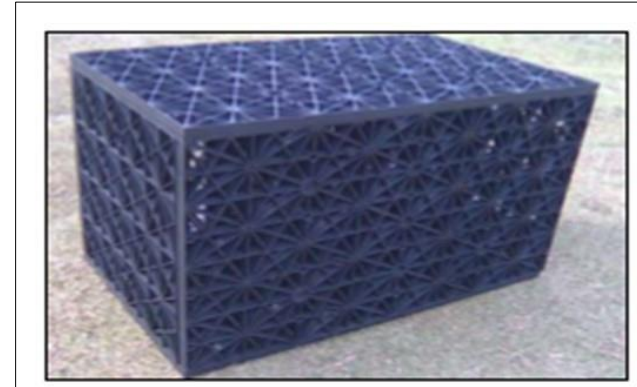

(1) Subsurface module in Taiping Health Clinic

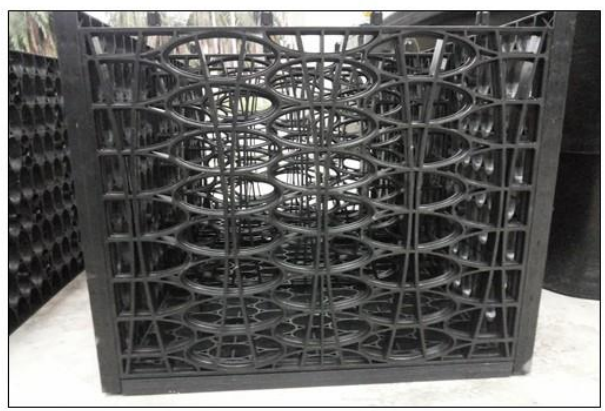

(3) The commercial RainSmart module

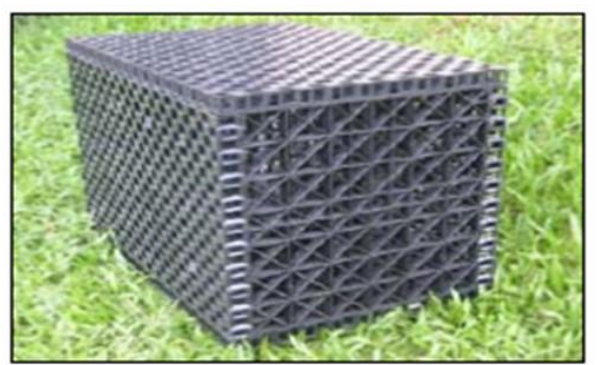

(2) Subsurface module in the BIOECODS

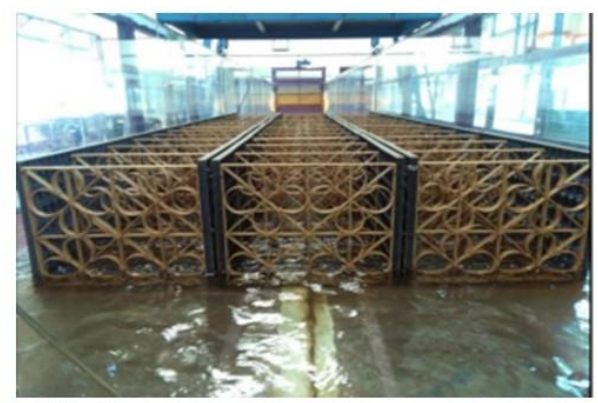

(4) REDAC module

Fig. 1: Different subsurface drainage modules tested by REDAC (Source: Kee, et al. [16])

\subsection{The Role of Drainage Modules in the BIOECODS Concept}

BIOECODS developed by River Engineering and Urban Drainage Research Centre (REDAC) was introduced in 2001. It is a system that adopts the concept of control at source, infiltration engineering and flow retardation to provide mitigation against flooding optimally by controlling the quantity and quality of stormwater runoff. Based on the recommendations of the Stormwater Management Manual for Malaysia (MSMA), USM Engineering campus has currently adopted this project for treatment of stormwater within the campus. The system uses grass swales, dry and wet as well as detention ponds and subsurface drainage modules. These components serve as alternatives to the traditional concrete engineering-based drainage to manage stormwater quantity and quality for the entire USM Engineering campus [17]. The system increases the lag time in the runoff, reduce the volume as well as the rate of runoff through enhanced infiltration and promote storage. Fig. 2 represents the pictorial views of the components of the technology in Malaysia [12, 17, 18].The BIOECODS system consist of several components that collectively work to form an effective treatment train for enhancing quality and quantity of stormwater in the USM Engineering campus as shown in Fig. 2 below [19]. This study elaborates more on the grassed swale and dry pond as both systems contain the subsurface drainage modules. 




Grassed swale



Constructed dry pond

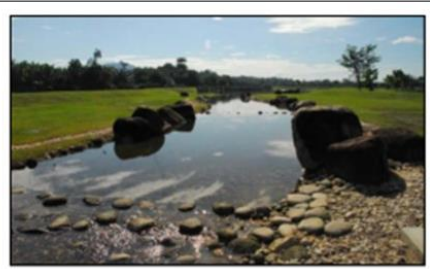

Meandering wading river

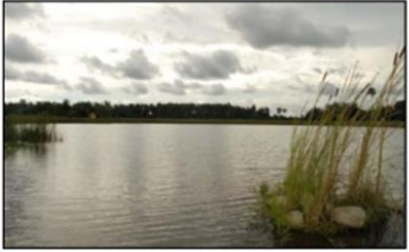

Recreational pond

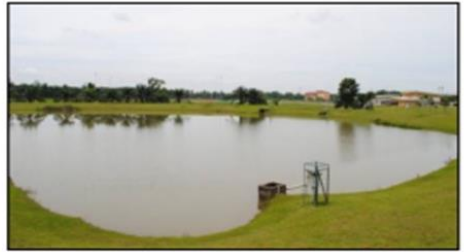

Constructed detention pond

Fig. 2: Components of BIOECODS (Source: Zakaria, et al. [11])

\subsubsection{Grassed swale}

The grassed swale also known as ecological swale [14] is a shallow, low-cost (when compared with concrete drains), open, bioengineered channel usually vegetated with different plants that are considered flood and erosion resistant. It is designed to enhance quality by first removing pollutant through vegetation filtration as well as promote infiltration [20]. It can retain stormwater for hours or days [21-23]. Majorly, the surface consists of grassed channel with gentle side slopes, shallow depth coupled with relatively low gradient. The subsurface layer consist of layer of sand or infiltration media, the modules which are enclosed by geotextile or a layer of hydronet to prevent sediment from entering the module as runoff enters the channel $[24,25]$. It first infiltrate through the grass, layer of sand and to the module. This process, as well as the surface friction from the vegetation tend to delay the flow. When the infiltrated water gets to the module it seeps through the perforation into the soil $100 \%$ (a process called exfiltration) until the soil becomes saturated from the side and bottom then storage will begin in the module [14]. When the water acquires enough kinetic energy (K.E.) as shown in Fig. 3 it flows downstream and join the river, pond or wetland system as the case may be $[26,27]$.

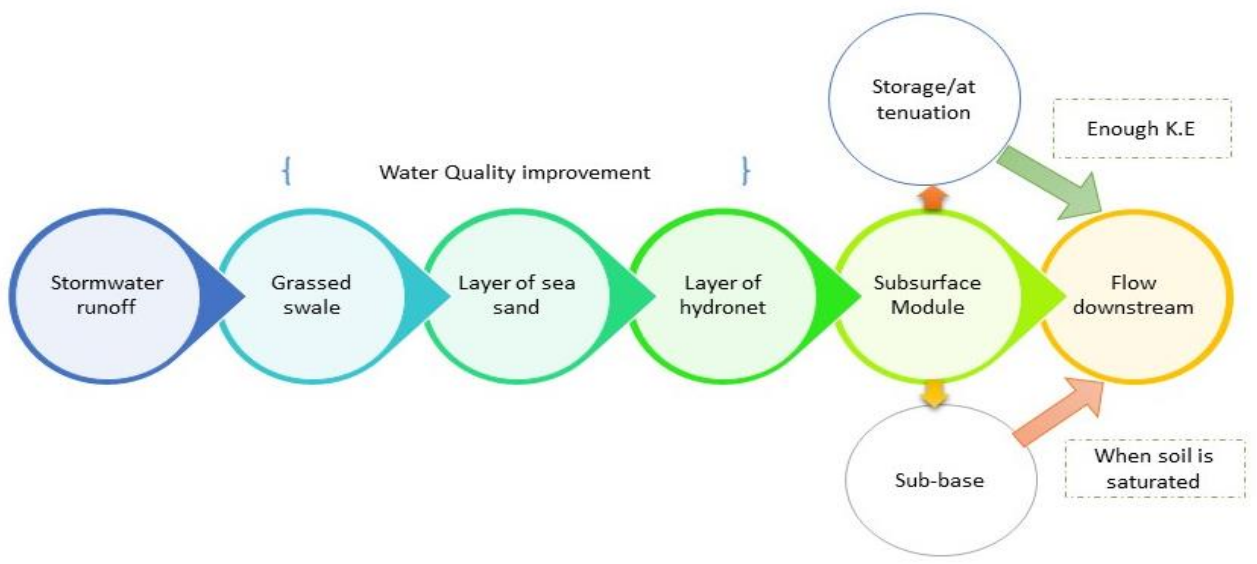

Fig. 3: Operational flow chart of bioswale 
The two mechanisms that enhance the quality of the stormwater in the swale are the vegetation which slows the water by providing roughness aiding in the removal of particles and associated pollutants. The second is the aerobic decomposition and chemical sorption that takes place as the stormwater infiltrates through the porous media to join the module at the subsurface level [28]. The ecological swales are categorized as type A, B and C depending on the number of single modules underneath. Type $\mathrm{A}$ has one, $\mathrm{B}$ has two and $\mathrm{C}$ has three numbers of single modules respectively as shown in Fig. 4. Through infiltration, the subsurface drainage modules become saturated and the runoff flows at the surface after series of rainfall events [11]. Fig. 5 shows a sample swale drain together with its components highlighted.

\section{Type-A}

\section{Type-B}


Fig. 4: Three types of ecological swales in the BIOECODS (Source: [17])
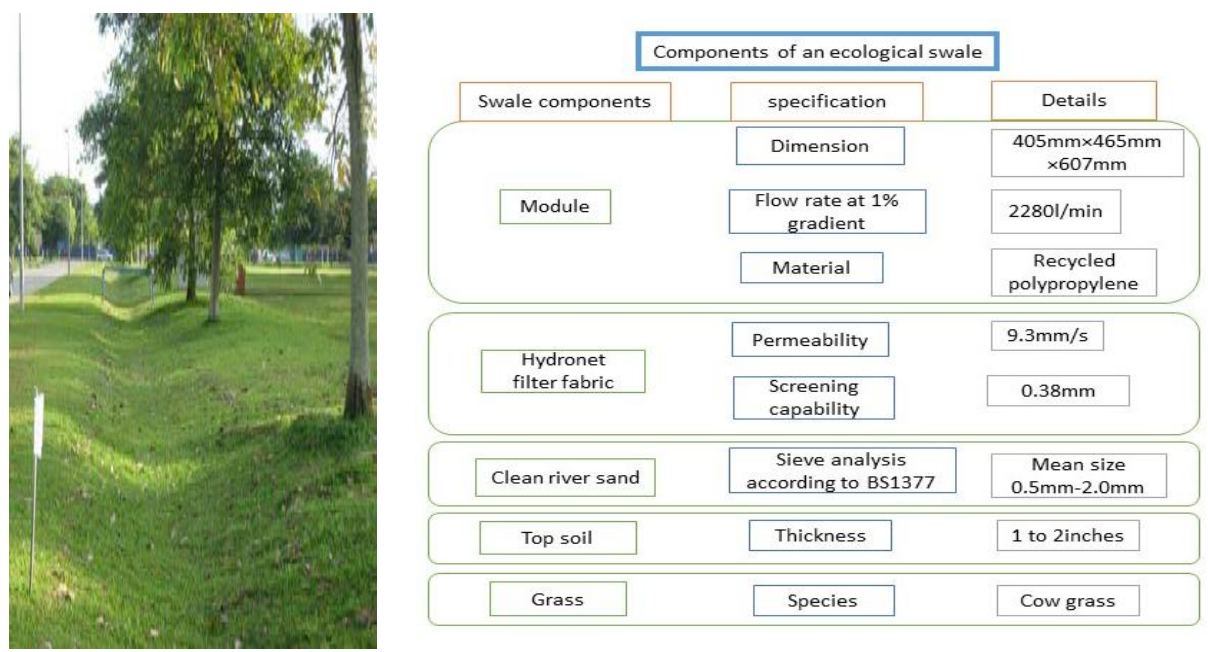

Fig. 5: Components of Ecological Swale (Source: Ghani, et al. [29]) 


\subsubsection{Dry pond:}

This is a multi-functional facility designed to store excess storm runoff from a catchment area. It is mostly considered as an Onsite Detention System (OSD) that can aid in reducing the peak flow at the downstream and can retain water up to a maximum depth of $150 \mathrm{~mm}$ [11]. Subsurface drainage module is also attached beneath the pond as shown in Fig. 6 and connected to the subsurface module of the swale. The stormwater infiltrates through the topsoil and river sand to the subsurface drainage module and then flows downstream [12, 17].

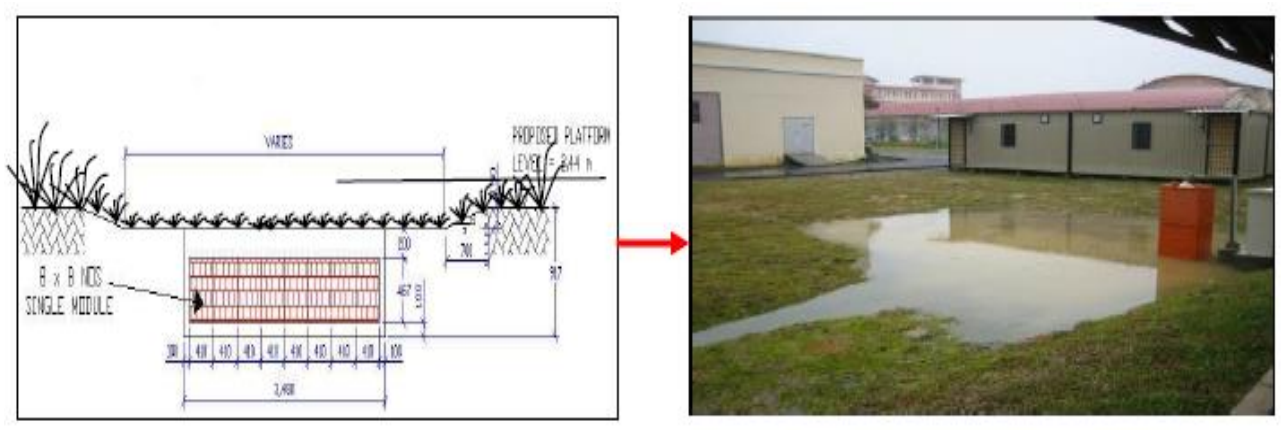

Fig. 6: Dry pond with drainage module under Ainan, et al. [12]

\subsubsection{Constructed Wetlands}

These are shallow, vegetated water bodies that use enhanced sedimentation, filtration and biological uptake processes to purify stormwater and remove pollutants. The outlets are configured to release flows during rainfall events based on the hydraulic retention time and back to dry weather water levels as shown in Fig. 7.

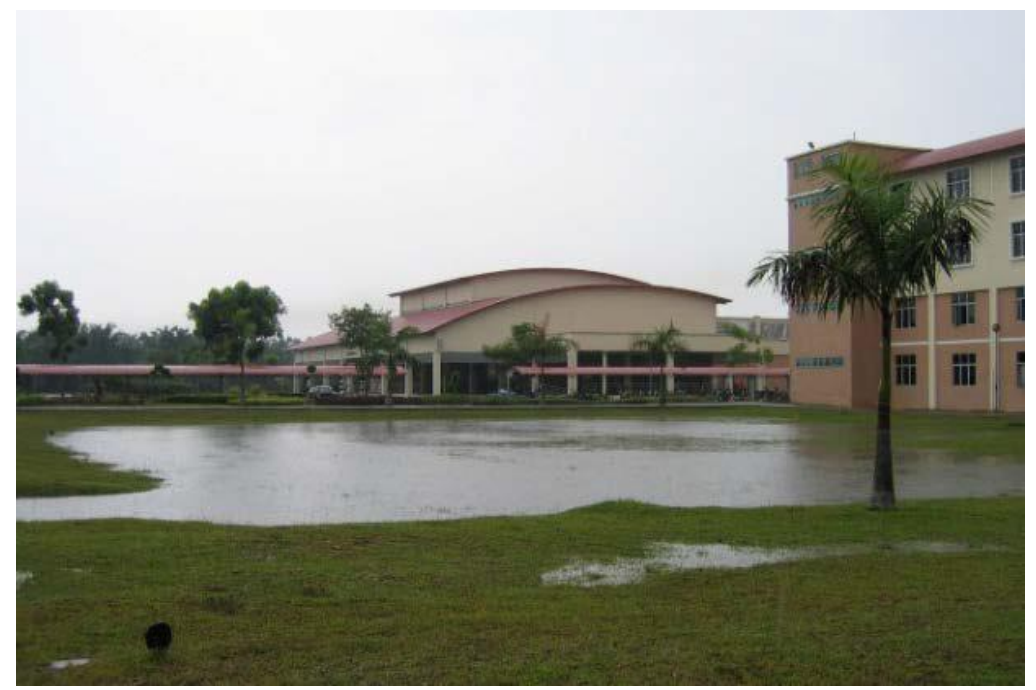

Fig. 7: Constructed wetland 


\subsubsection{Detention Ponds:}

These are the most important elements or storage facilities for ensuring the peak discharge (post-development) is not greater than the peak discharge (pre-development). These types of ponds are designed for flow attenuation from urbanized areas through the use of regulated outlet structures. The end product of this system is expected to provide an improvement in the aesthetic value of the surrounding areas with the existence of the "Crystal Clear Blue Water Lake" at the downstream end of the BIOECODS as shown in Fig. 8.

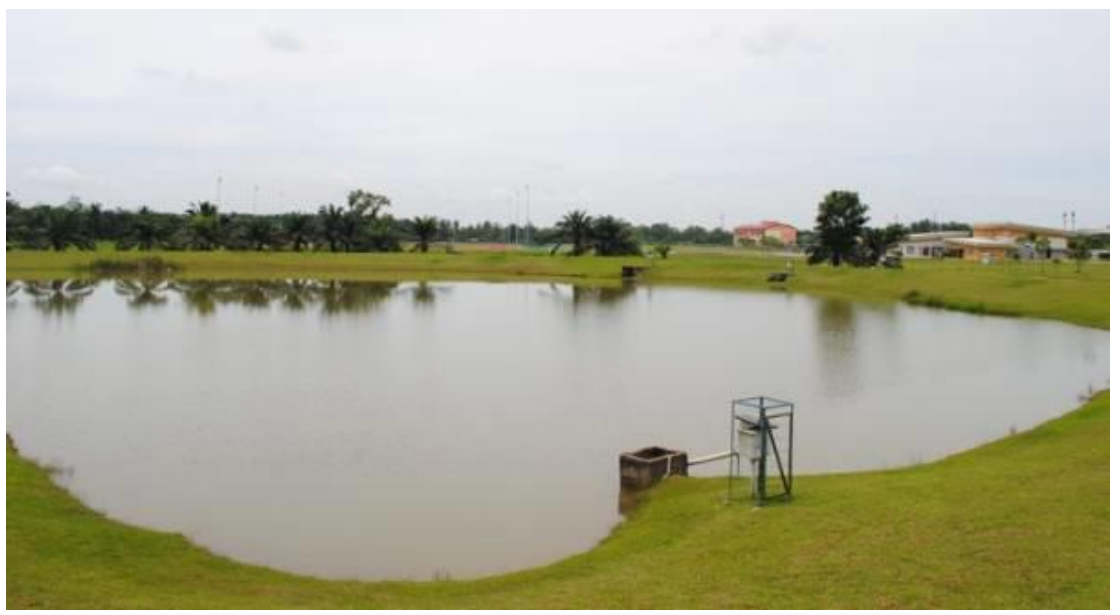

Fig. 8: Detention pond

\subsubsection{Wading River:}

This has two components including the main channel and the floodplains as shown in Fig. 9. It is designed to basically convey runoff from the wetlands to the recreational pond before finally discharging to Sungai Kerian River in USM.

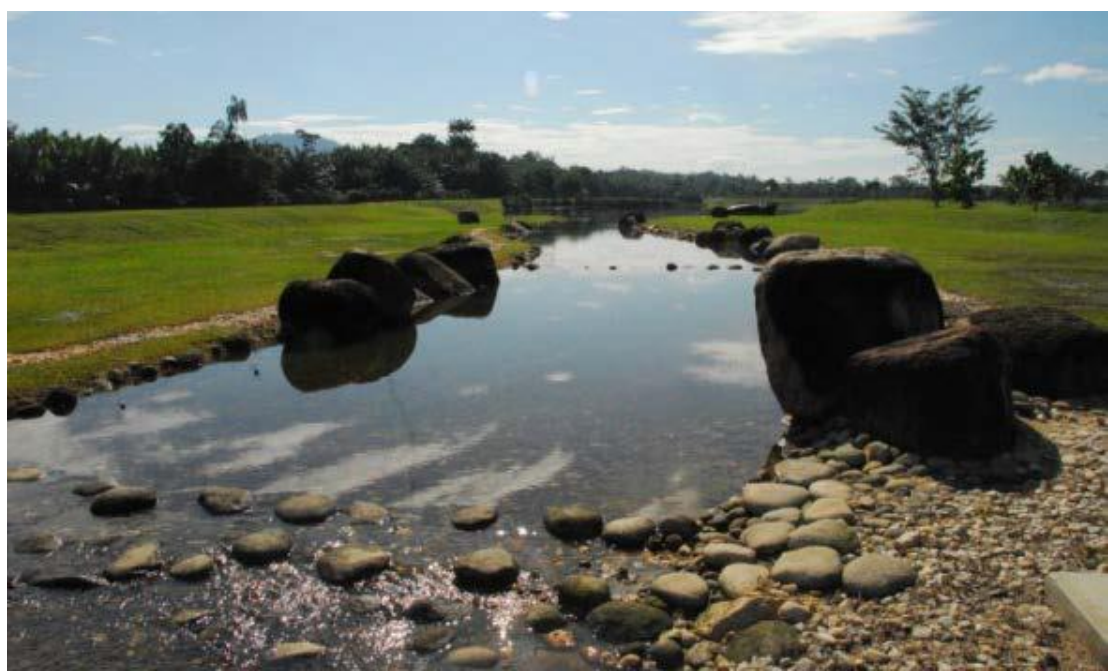

Fig. 9: Wading river 


\subsubsection{Recreational Pond:}

This is the end product of the BIOECODS system and is expected to improve the aesthetic value for surrounding areas with the existence of the "Crystal Clear Blue Water Lake" as shown in Fig. 10 [17].



Fig. 10: Recreational pond

In all the components of the BIOECODS described above, the drainage module is included in the swale and dry pond. It plays a key role in ensuring the flow attenuation to mitigate against flooding, quality and quantity enhancement. Therefore, the study of its characteristics and behavior is extremely important to ensure the optimal performance of the system for efficient flood mitigation.

\section{Review of previous works on BIOECODS and drainage module}

A lot of processes take place in the BIOECODS including sedimentation, filtration, seepage, biodegradation, etc and all contribute to reducing the amount of pollutants [26] [17, 30]. Although the system is less than two decades in existance [14], a signinficant amount of research had been carried out on the general and specific characteristics of the subsurface drainage modules. The most recent work on the BIOECODS is the one by Muhammad, et al. [31] who developed models using Artificial Neural Network (ANN) coupled with some experimental work for verification. The author(s) developed the model and confirmed an improvement in performance even though did not specifically compared the developed model with other existing model. Same authors Muhammad, et al. [32] and Muhammad, et al. [31] carried out experimental works on the swale, develop prediction models using the Genetic Expression Programming (GEP) and ANN to study variation in flow resistance in the vegetated channel. The work compared the performance of ANN and the GEP and proposed that the latter was preferred as it produced a physical equation. The author based his finidings on when the flow is subcritical with Froude number less than 1.0 and did not explain their behaviour when the Froude number is above 1.0. The novelty in this research is in the development of the models which are applicable to the BIOECODS to predict flow resistance and behaivours of other hydraulic parameters.

In the early years of the system, Ghani, et al. [29] studied the theoretical aspects of the technology in general with specific detail on the concept, design, and construction. The 
author highlighted the key functions of the system which include promoting stormwater infiltration from impervious surfaces, enhancing water quality through the use of the treatment train concept. This is achievable by utilizing the bio-ecological swales and ponds (dry and wet) as clearly shown in Fig. 11. The last function of the system according to the author is ensuring controlled release of the stormwater at the downstream river. This study introduced the basic concept of the system, providing clear explanation on the operational mechanism of the BIOECODS system. In similar studies by Ainan, et al. [12] and Benisi, et al. [18], flow attenuation had been considered one of the most effective ways to describe the effectiveness of an ecological swale in terms of quantity and quality control. The effectiveness of an ecological swale is considered from the aspect of quantity control in term of peak flow attenuation. In the end, it was clearly shown that with a rainfall-catchment response time of 40mins, the BIOECODS has the potential to create flow attenuation up to $60-75 \%$ [33]. Also, the retention behaviour of the dry pond was confirmed with the use of ultrasonic water level sensor to have taken up to 20 hours for stormwater infiltration and emptying. The uniqueness of this research is in its ability to use real time rainfall data to determine the flow attenuation in the system.

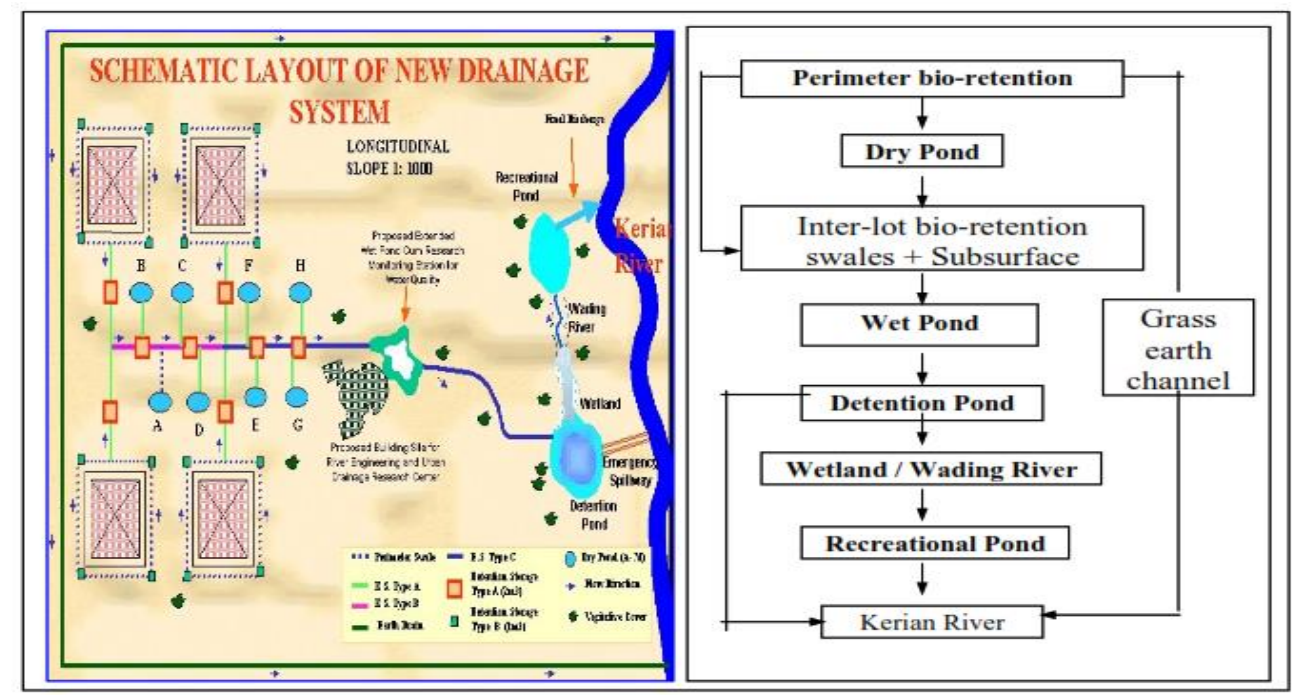

Fig. 11: BIOECODS Design Concept in USM (Source: Ghani, et al. [29])

Other relevant areas studied include water quality and quantity control by Zakaria, et al. [17], whose study showed a good agreement between the observed and simulated data in terms of peak flow and runoff volume. This is a clear confirmation that the feature of the BIOECODS was clearly represented in the XP-SWMM modelling software used. The research was purely numerical without clear experimental data to validate the findings of the model. In the same line, environmental planning as it relates to the modules was studied by Sidek, et al. [34], who introduced the concept of the BIOECODS as utilizing the control at source followed by detailed description of technical and construction activities including costs incurred and marketability of the system. In the end, the study identified some Engineering challenges which are essential to achieving integrated approach towards urban stormwater environmental planning and management. This study did not consider the life span of the system as well as its maintenance schedule with the passage of time. Similarly, flow patterns and hydraulic characteristics were studied by Ahmad, et al. [19] and [14]. Both findings revealed an understanding of the hydraulic flow resistance of the grassed swale in terms of Manning's roughness coefficient which was shown to increase with a decrease in 
flow depth although the latter author utilizes experimental techniques at different discharge and slope conditions. The Manning's roughness coefficient $(\mathrm{n})$ is recommended as a fundamental parameter to estimate roughness in different channels [35]. Also, hydraulic performance of the subsurface drainage modules was studied by Lai, et al. [36], with results that showed the capability of the subsurface drainage module in enhancing groundwater recharge and effectiveness in reducing peak flow runoff.

Sidek, et al. [34] studied the flow pattern through modular channels and reported that subsurface modules change the flow velocity in channels and that the average, minimum as well as maximum velocities at the moudle's sides are higher than those inside the modules and hence concluded that drainage modules effectively increase dissolved oxygen with respect to distance, time and velocity. Furthermore, Muhammad, et al. [20] studied hydraulic assessment of grassed swale as a bioengineered channel and found that the velocity at the center line in the grassed swale ranges between 0.05 -_ $0.76 \mathrm{~m} / \mathrm{s}$ and a decrease in shear stress in the range of $3.47-6.59 \mathrm{~N} / \mathrm{m}^{2}$ was reported. This behaviour is similar with that of subsurface module. Although all values were within the allowable limit, it was concluded that this relationship could be used in developing a resistant grassed swale for Malaysia. Also, Muhammad, et al. [33], measured flow resistance through the subsurface modules and found a decrease in the upstream discharge of less than $40 \%$ which is a clean evidence of flow attenuation in the module. In addition, Manning's roughness coefficient as it relates to flow resistance was studied by Kee, et al. [16] and in the end, equations that relate the Manning's roughness coefficient with the modules were developed. Lastly, performance optimization of the modules was studied by Cunha, et al. [37] and Wang, et al. [38] their findings were later highlighted in this paper. Overall, the BIOECODS is considered effective in terms of providing flow attenuation, ensuring quality and quantity control of the stormwater with great prospects of mitigating flooding in Malaysia. Recently, several studies have been conducted to determine the flow resistance and Manning's $\mathrm{n}$ at the channel with submerged and unsubmerged vegetation [39]. In the vegetated channel, Manning's coefficient is known as the retardance coefficient and the plant's height is recognized as a significant parameter to estimate roughness [40].

\section{Performance evaluation methods of the drainage modules}

Different methods of assessment were employed by past researchers to evaluate the performance of the subsurface drainage modules including field, numerical and laboratory experiments. Among these, Zakaria, et al. [17] used XP-SWMM to model the BIOECODS using the link node concept. In this study, initial losses, infiltration and depression parameters were considered among the hydrologic and hydraulic parameters for calibrating the results under series of rainfall events and flow data from the field. This study did not develop a direct validation of the numerical findings with experimental results. Others include Faram, et al. [41] who carried out performance evaluation using Computational Fluid Dynamics (CFD) and validated using experimental results in the laboratory by introducing some tracer materials for different cases of with and without under-pipes.

Sánchez-Beltrán, et al. [42] characterizes the hydraulic performance of the drainage modules using CFD, validated with experimental results and developed a 1D model using SWMM for adjustments. From the Fig. 12 and Fig. 13 the attenuation can clearly be visible as the water passes through the system with single and multiple modules. The depth is seen to decrease uniformly with increase in the number of modules. The study concluded that the energy dissipation which is responsible for flow attenuation is concentrated at three points which include the inlet, outlet and distributed along the module. The authors strongly recommended CFD as a useful tool in characterizing the performance of modules. Also, 
Jarman, et al. [43] in his review paper shared the same view with Sánchez-Beltrán, et al. [42] and concluded that most fluid processes and associated phenomena can be studied using CFD and went further to state that the technique can be applied to study urban drainage systems, flow field performance, particle behaviors, water-free surface and residence time distribution.

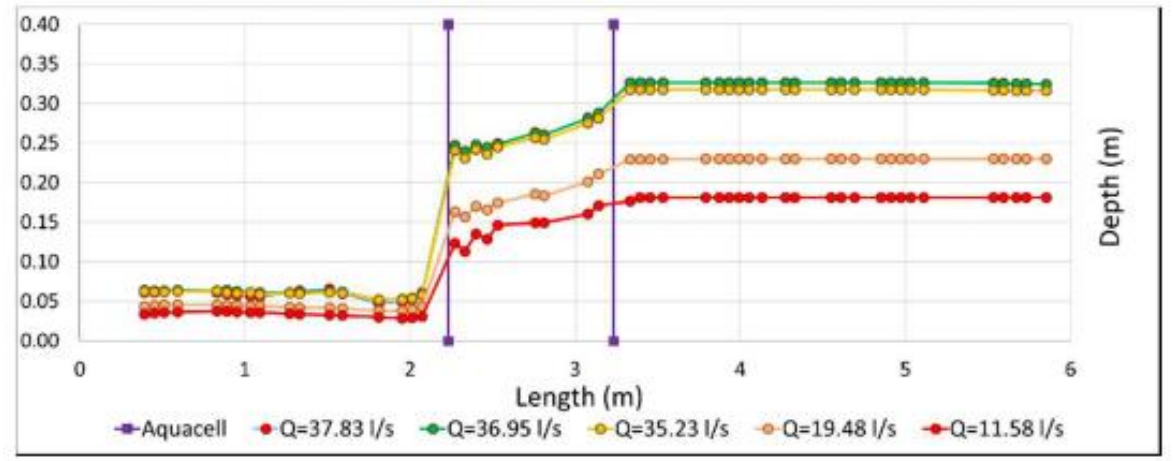

Fig. 12: Laboratory vs CFD for various Qs on a single module. (Source: Sánchez-Beltrán, et al. [42])

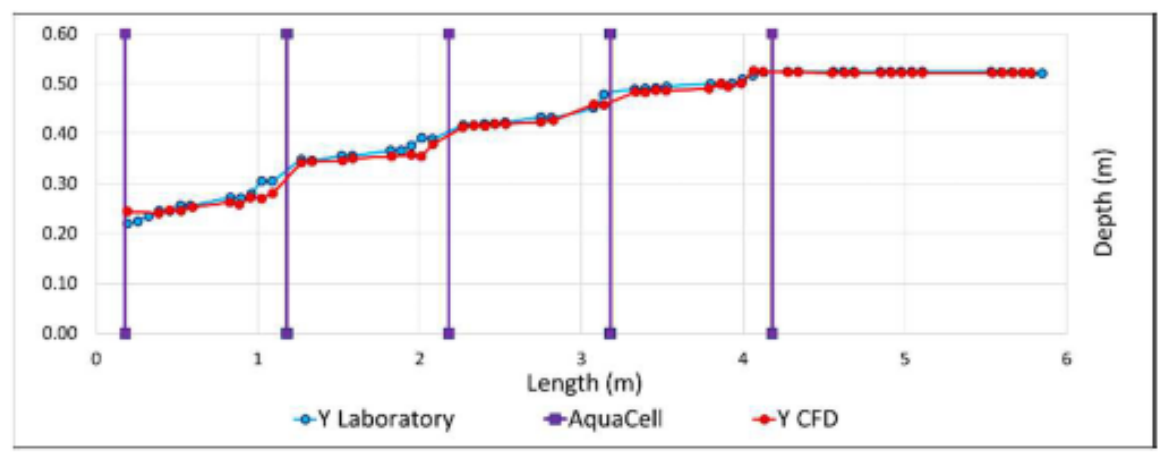

Fig. 13: CFD vs Experimental for $Q=37.831 /$ s (Source: Sánchez-Beltrán, et al. [42])

Kee, et al. [16] uses strongly laboratory experiments to determine Manning's roughness coefficient and predicted the performance of the modules. Also, Benisi, et al. [18] studied the effectiveness of BIOECODS (with subsurface drains among the components) in ensuring flow attenuation by utilizing both numerical (infoWorks) and field experiment using rainfall events with results that show attenuation of up to $60-75 \%$ and an increase of lag time by up to 20 mins. In the field, the subsurface drainage modules were studied by Ahmad, et al. [19] and Lai, et al. [36] who used series of rainfall events. A similar study by Ainan, et al. [12] uses up to nine (9) different rainfall event to arrive at a minimum volume reduction of $19.4 \%$ at the surface channel and $22.7 \%$ for subsurface which confirms flow attenuation. Similarly, Muhammad, et al. [33] assessed the flow resistance through the subsurface drainage modules in the field and validated with laboratory experiments. The author was able to estimate a decrease in the upstream discharge in the range of 30.03 to $37.49 \%$ although he uses a new module design called the Rainsmart (dimension $710 \mathrm{~mm} \times 400 \mathrm{~mm} \times 400 \mathrm{~mm}$ ). In the same line, Lai, et al. [36] carried out a case study on a small scale sustainable drainage system which consist of grassed swale with subsurface drainage module, the main objective was to investigate the performance of the subsurface drainage module in managing urban stormwater runoff in the catchment area. The results show that the subsurface drainage module is effective in reducing peak flow of surface runoff as well as in enhancing groundwater recharge in the study area. 


\section{Established concepts in the subsurface drainage modules}

In an earlier study by Sidek, et al. [44] on the flow pattern and hydraulic capacity of the drainage modules, turbulence flow and a variation in velocity due to pattern and internal structure of the modules was observed. Also, the maximum, minimum and average velocity distributions beside the module were observed to be higher than within the modules. Due to the fact that flow profile in the module was observed to resemble those of pipe flow and open channel as shown in Fig. 14, the research concluded that the velocity distribution in the pipe flow resembles closely to that of the drainage modules.

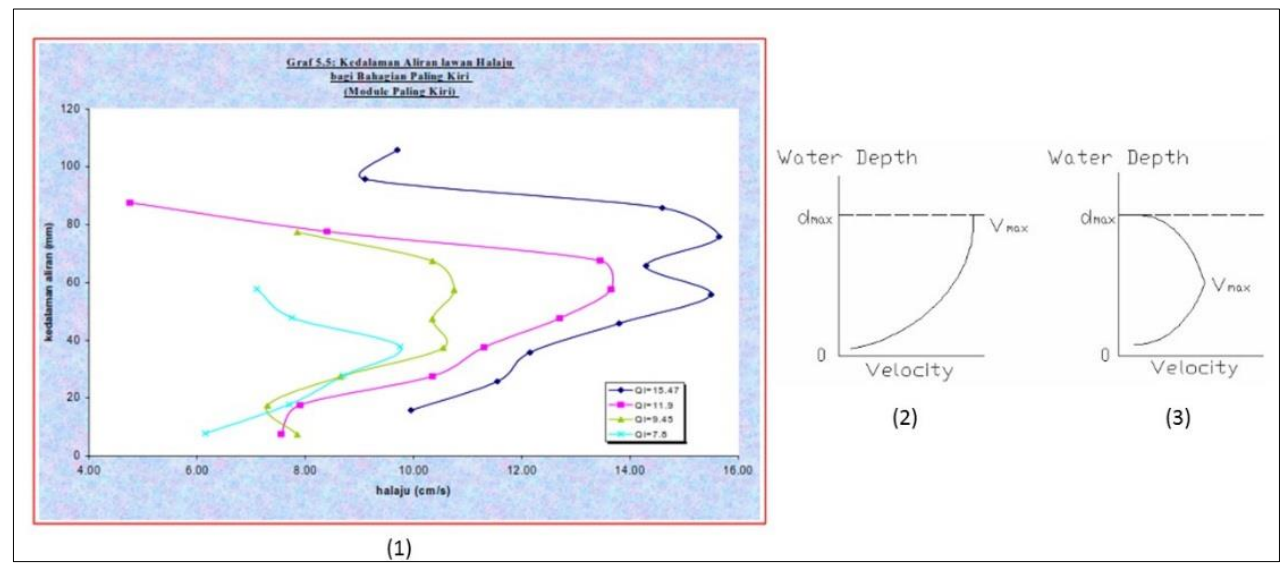

Fig. 14: (1) Flow depth vs velocity in the drainage module, (2) and (3) Open channel and Pipe flow depth velocity relationship (Source: Sidek, et al. [9] and Lai, et al. [14])

\subsection{Subsurface drainage modules and water quality control}

The capacity of the subsurface drainage modules in pollutant removal was tested by Sidek, et al. [9] and found that the modules have little metallic content removal with Zinc, Caprum, Nickel and Plumbum as low as $10.9 \%, 38.7 \%, 33.3 \%$ and $15.9 \%$ respectively. This is ascribed to the slow chemical decomposition process in the module. Also, the drainage modules in the same study were observed to increase dissolved oxygen (DO) with respect to time, velocity and distance as demonstrated in Fig. 15 and Fig. 16. In addition, the subsurface modules in swale system together can remove the Total Suspended Solids (TSS) and Total Phosphorus (TP) [45] which are essentially tagged among the three pollutant parameters for stormwater quality studies[46]. 


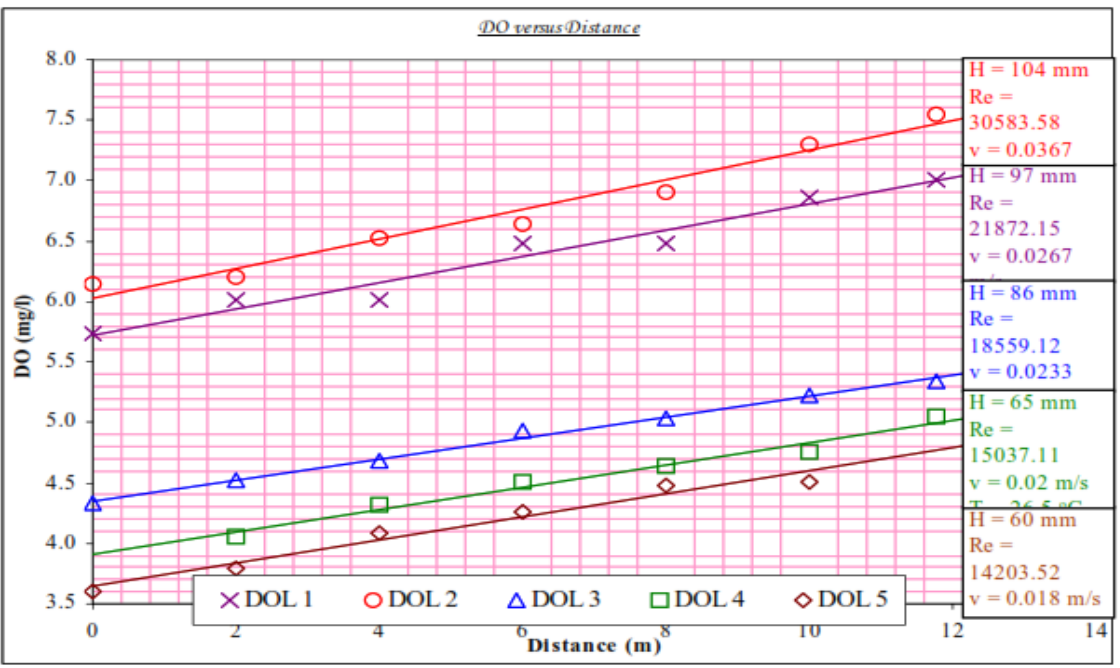

Fig. 15: DO vs Distance in the drainage module Sidek, et al. [9]



Fig. 16: DO vs Time in the drainage module (Source: Sidek, et al. [9])

\subsection{Challenging issues in the technology}

In less than two decades of introducing the subsurface drainage module technology in Malaysia, the structures had proved to be extremely useful and have great potential in providing the stormwater quantity and quality control and can attenuate flows especially in the BIOECODS. The subsurface drainage modules have been found to be effective components in the BIOECODS towards ensuring adequate stormwater management in a nonerosive manner for rainfall events with average return interval (ARI) less than three months. This is achieved by groundwater recharge through seepage of water into its surrounding soil (sides and bottom). The modules have also been found to cater for a percentage of surface runoff volume with values ranging from $15.2 \%-20.5 \%$ for storm events with ARI less than 
6-months. Series of studies are still ongoing to ascertain and improve their performances in the BIOECODS system. However, some challenges still remain and should strongly be considered in subsequent studies.

Among these challenges is the fact that different drainage modules have been found to possess different flow attenuations ranging from high $(n>0.1)$ to very low which in each case can lead to flooding. In all cases there is a great effect on the flow velocity and hydraulic performance of the subsurface drain. Literature survey revealed that only very few studies explained the physics of the interaction between the fluid flow and the solid bodies of the modules as well as clear visualization of these interactions. Through optimization of the flow pattern and hydraulic characteristics, it is expected to improve the performance of these modules to optimum levels.

In addition, Kee, et al. [16] highlighted that the drainage modules applied in the BIOECODS at USM Engineering campus and Taiping Health Clinic have been found to have high roughness which provides flow attenuation. However, high roughness is not a suitable factor in the design of conveyance system since it causes the stormwater flow to be slower than infiltration rate into the tank. This can have a great effect on the BIOECODS and can result in causing localized water ponding [16]. REDAC has designed and built another module (REDAC module) which is expected to provide less flow attenuation and to serve as a suitable conveyance system since it has larger surface openings. However, this module's is still under investigation. Sidek, et al. [9] highlighted that despite the presence of the modules underneath, the grassed swale is not effective in reducing bacteria levels and it requires further treatment especially through the constructed wetlands. Also, the swales if designed improperly, they can have very little pollutant removal. However, the swales with modules are limited as individual drainage channels cannot treat flows from more than 2 hectares of land.

Although from the different experiments carried out, the BIOECODS system seems to have good performance after about two decades in operation. There is concern over the loss of efficiency during the design life especially the infiltration capacity of the module, the state of the geotextile and hydronet over time [7]. Maintenance and efficiency evaluation should be considered top priority in order to monitor performance, although in the case of BIOECODS it simply means maintenance of the grass plant cover [9]. Sustainable drainage systems are generally managed with reduced cost. In other systems similar to BIOECODS such as the permeable pavement as reported by [47] that after 20 years of operation, it lost up to $80 \%$ of its infiltration rate. Based on other studies, sediments and other pollutants are trapped at the upper layer where remedial work are carried out similar to BIOECODS [4850]. For the sake of accuracy in performance, there should be an onsite methodology to assess the permeability, rate of clogging, condition of the geotextile and hydronet over time. The detail of the cost appraisal in designing and developing the BIOECODS in comparison with traditional concrete drain should be provided.

\section{Conclusion}

This study reviewed the existing literature and highlighted the key advancement and challenges in subsurface drainage module technology. The modules had been found to play key roles in the BIOECODS especially in providing flow attenuation, quality and quantity control of stormwater. However, more work is required on the hydraulic characteristics, flow attenuation and direct validation methods between field, laboratory, and numerical data. There is concern over the loss of efficiency during the design life especially the infiltration capacity of the module, the state of the geotextile and hydronet over time. Also, the modules had been found to have varying attenuation levels. The optimum performance of the module should be considered in module selection and BIOECODS design as improper selection of 
the modules can result in an unnecessary ponding and flooding instead of mitigating the flood. CFD had been identified and recommended as a great tool that can give the detailed physics between the fluid flow and solid bodies and can provide clear visualization of these interactions. The study also recommends that there should be an onsite methodology to assess the permeability, rate of clogging and condition of the geotextile as well as the hydronet over time.

\section{Acknowledgement}

The authors acknowledged the STIRF grant (0153AA-F49), Universiti Teknologi PETRONAS, Malaysia and River Engineering and Urban Drainage Research Centre (REDAC), Universiti Sains Malaysia.

\section{References}

1. S. Paulo, "Manual de Drenagem e manejo de águas pluviais: aspectos tecnológicos, diretrizes para projetos, ed," SMdDU (SMDU), São Paulo, p. 128, 2012.

2. L. García, J. Barreiro-Gomez, E. Escobar, D. Téllez, N. Quijano, and C. OcampoMartínez, "Modeling and real-time control of urban drainage systems: A review," Advances in Water Resources, 85, pp. 120-132, 2015.

3. S. Lukman and A. Abdurrasheed, "Improvement Design of Storm Sewer Network for Flood Control," Frontiers in Environmental Engineering, 2014.

4. M. J. Hammond, A. S. Chen, S. Djordjević, D. Butler, and O. Mark, "Urban flood impact assessment: A state-of-the-art review," Urban Water Journal, 12, pp. 14-29, 2015.

5. R. Field and A. N. Tafuri, The use of best management practices (BMPs) in urban watersheds: DEStech Publications, Inc, 2006.

6. T. D. Fletcher, W. Shuster, W. F. Hunt, R. Ashley, D. Butler, S. Arthur, et al., "SUDS, LID, BMPs, WSUD and more-The evolution and application of terminology surrounding urban drainage," Urban Water Journal,12, pp. 525-542, 2015.

7. M. Marchioni and G. Becciu, "Experimental results on permeable pavements in urban areas: a synthetic review," International Journal of Sustainable Development and Planning,10, pp. 806-817, 2015.

8. M. Marchioni and G. Becciu, "Permeable pavement used on sustainable drainage systems (SUDs): a synthetic review of recent literature," WIT Transactions on the Built Environment, 139, 2014.

9. L. M. Sidek, E. Tak, A. Ghani, N. Zakaria, and R. Abdullah, "Bio-Ecological Drainage Systems (Bioecods): An integrated approach for urban water environmental planning," in Seminar on Water Environmental Planning: Technologies of Water Resources Management, 2002, pp. 15-16.

10. T. D. Fletcher, H. Andrieu, and P. Hamel, "Understanding, management and modelling of urban hydrology and its consequences for receiving waters: A state of the art," Advances in water resources,51, pp. 261-279, 2013.

11. N. A. Zakaria, A. A. Ghani, and C. K. Chang, "MSMA 2 nd Edition-Application of Green Infrastructures for Solving Sustainable Urban Stormwater Management Challenges," 2014.

12. A. Ainan, N. Zakaria, A. A. Ghani, R. Abdullah, L. Sidek, M. Yusof, et al., "Peak Flow Attenuation Using Ecological Swale and Dry Pond," Advances in Hydro-Science and Engineering, VI, 2003. 
13. M. E. Barber, S. G. King, D. R. Yonge, and W. E. Hathhorn, "Ecology ditch: A best management practice for storm water runoff mitigation," Journal of Hydrologic Engineering, 8, pp. 111-122, 2003.

14. S. Lai, L. Kee, N. Zakaria, A. A. Ghani, C. Chang, and C. Leow, "Flow Pattern and Hydraulic Characteristic for Subsurface Drainage Module," in International Conference on Water Resources (ICWR 2009), Kedah, Malaysia, 2009.

15. I. Andrés-Doménech, A. Montanari, and J. Marco, "Efficiency of storm detention tanks for urban drainage systems under climate variability," Journal of Water Resources Planning and Management,138, pp. 36-46, 2011.

16. L. C. Kee, N. A. Zakaria, T. L. Lau, C. K. Chang, and A. A. Ghani, "Determination of manning's n for subsurface modular channel," 2011.

17. N. A. Zakaria, A. Ab Ghani, R. Abdullah, L. Mohd. Sidek, and A. Ainan, "Bioecological drainage system (BIOECODS) for water quantity and quality control," International Journal of River Basin Management, 1, pp. 237-251, 2003.

18. G. H. Benisi, H. L. Sai, B. C. Hooi, and C. R. Jie, "Effectiveness of BIOECODS for peak flow attenuation: an appraisal using InfoWorks SD," Hydrological Sciences Journal, 62, pp. 421-430, 2017.

19. N. A. Ahmad, A. A. Ghani, and N. A. Zakaria, "Hydraulic characteristic for flow in swales," Rn, 6, p. 1, 2011.

20. M. Muhammad, K. Yusof, M. Mustafa, and A. A. Ghani, "Hydraulic assessment of grassed swale as bioengineered channel," in Engineering Challenges for Sustainable Future: Proceedings of the 3rd International Conference on Civil, Offshore and Environmental Engineering (ICCOEE 2016, Malaysia, 15-17 Aug 2016), 2016, p. 273.

21. K. E. Lee, M. Mokhtar, M. M. Hanafiah, A. A. Halim, and J. Badusah, "Rainwater harvesting as an alternative water resource in Malaysia: potential, policies and development," Journal of Cleaner Production,126, pp. 218-222, 2016.

22. DID, "Urban storm water management manual for Malaysia. Department of Irrigation \& Drainage (DID) Malaysia.," 2012.

23. SUDS, "Sustainable Drainage Manual: Guidance on Design of Swales. Construction Industry Research and Information Association. In: (CIRIA) (ed.) C753 ed.," 2015.

24. E. Kamphorst, J. Chadoeuf, V. Jetten, and J. Guérif, "Generating 3D soil surfaces from 2D height measurements to determine depression storage," Catena,62, pp. 189-205, 2005.

25. A. Deletic, "Modelling of water and sediment transport over grassed areas," Journal of Hydrology, 248, pp. 168-182, 2001.

26. N. A. Zakari, "MSMA 2 nd Edition-Application of Green Infrastructures for Solving Sustainable Urban Stormwater Management Challenges."

27. N. A. Zakaria, A. A. GHANI, and T. L. LAU, "Securing water for future generations through sustainable urban drainage designs: A peek into the Bio-ecological drainage system (BIOECODS)," in 3d Internationa Conference on Managing Rivers in 21st Century: Sustainable Solutions For Global Crisis of Flooding, Pollution and Water Scarcity, Penang, Malaysia, 2011.

28. M. Borst, S. Struck, S. Muthukrishnan, A. Selvakumar, and T. O'Connor, "Swale Performance for Stormwater Runoff," in Low Impact Development: New and Continuing Applications, ed, 2009, pp. 182-190.

29. A. A. Ghani, N. Zakaria, R. Abdullah, M. Yusof, L. Sidek, A. Kassim, et al., "BioEcological Drainage System (BIOECODS): Concept, Design and Construction," in 6th International Conference on Hydroscience and Engineering (ICHE-2004), May 30-June 3, Brisbane, Australia, 2004. 
30. A. A. Ghani, N. Zakaria, R. Abdullah, M. Yusof, L. M. Sidek, A. Kassim, et al., "BioEcological Drainage System (BIOECODS): Concept, Design and Construction," in Internariond Conference on HydroScience and Engineering, Brisbane, Australia, 2004.

31. M. M. Muhammad, K. W. Yusof, M. R. U. Mustafa, N. A. Zakaria, and A. A. Ghani, "Artificial Neural Network Application for Predicting Drag Coefficient in Flexible Vegetated Channels," Journal of Telecommunication, Electronic and Computer Engineering (JTEC), 10, pp. 99-102, 2018.

32. M. M. Muhammad, K. W. Yusof, M. R. U. Mustafa, N. A. Zakaria, and A. Ab. Ghani, "Prediction Models for Flow Resistance in Flexible Vegetated Channels," International Journal of River Basin Management, pp. 1-26, 2018.

33. M. Muhammad, K. Yusof, M. Mustafa, N. Zakaria, and A. A. Ghani, "Hydraulic Performance of Sub-surface Drainage Module," in IAHR World Congress, Kuala Lumpur, Malaysia 2017, pp. 6059-6066.

34. L. Sidek, E. Tak, A. Ghani, N. Zakaria, and R. Abdullah, "Bio-Ecological Drainage Systems (Bioecods): An integrated approach for urban water environmental planning," Water Environmental Planning: Towards Integrated Planning and Management of Water Resources for Environmental Risks.(Eds.) Abdullah, A., Okada, N., and Yusoff, MK, pp. 539-567, 2004.

35. H. M. Azamathulla, Z. Ahmad, and A. A. Ghani, "An expert system for predicting Manning's roughness coefficient in open channels by using gene expression programming," Neural Computing and Applications,23, pp. 1343-1349, 2013.

36. S. Lai, L. Kee, and N. Zakaria, "Subsurface Drainage Module Performance Study in Managing Urban Stormwater (Case Study: Taiping Health Clinic Type 2)," in World Engineering Congress, Kuching, Sara, Malaysia, 2010.

37. M. C. Cunha, J. A. Zeferino, N. E. Simões, and J. G. Saldarriaga, "Optimal location and sizing of storage units in a drainage system," Environmental Modelling \& Software, 83, pp. 155-166, 2016.

38. M. Wang, Y. Sun, and C. Sweetapple, "Optimization of storage tank locations in an urban stormwater drainage system using a two-stage approach," Journal of Environmental Management,204, pp. 31-38, 2017.

39. Y.-C. Chen, S.-P. Kao, J.-Y. Lin, and H.-C. Yang, "Retardance coefficient of vegetated channels estimated by the Froude number," Ecological Engineering, 35, pp. 1027-1035, 2009.

40. C. Conesa-García, J. L. Sánchez-Tudela, P. Pérez-Cutillas, and F. Martínez-Capel, "Spatial variation of the vegetative roughness in Mediterranean torrential streams affected by check dams," Hydrological Sciences Journal,63, pp. 114-135, 2018.

41. M. Faram, I. Guymer, and A. J. Saul, "Assessment of modular block stormwater storage systems," in Novatech: 5th International Conference on Sustainable Techniques and Strategies in Urban Water Management, 2004, pp. 235-242.

42. H. Sánchez-Beltrán, C. M. Rodríguez, J. B. Triviño, P. Iglesias-Rey, J. S. Valderrama, and F. Martínez-Solano, "Characterization of Modular Deposits for Urban Drainage Networks Using CFD Techniques," Procedia Engineering,186, pp. 84-92, 2017.

43. D. Jarman, M. Faram, D. Butler, G. Tabor, V. Stovin, D. Burt, et al., "Computational fluid dynamics as a tool for urban drainage system analysis: A review of applications and best practice," 2008.

44. L. M. Sidek, N. A. Zakaria, A. A. Ghani, and R. Abdullah, "The use and development of bio-ecological drainage systems (BIOECODS) under tropical climate," in Proceedings of the 2 nd World Engineering Congress. July, 2002, pp. 22-25.

45. C. Pratt, "Sustainable drainage: A review of published material on the performance of various SUDS components," Prepared for the Environment Agency. SUDS Science Group/99705.015, 2004. 
46. J. Yazdi, "Water quality monitoring network design for urban drainage systems, an entropy method," Urban Water Journal,15, pp. 227-233, 2018.

47. S. Borgwardt, "Long-term in-situ infiltration performance of permeable concrete block pavement," in Proceedings of the 8th International Conference on Concrete Block Paving, San Francisco, CA, USA, 2006.

48. C. Dierkes, L. Kuhlmann, J. Kandasamy, and G. Angelis, "Pollution retention capability and maintenance of permeable pavements," in Global Solutions for Urban Drainage, ed, 2002, pp. 1-13.

49. C. Gerrits and W. James, "Restoration of infiltration capacity of permeable pavers," in Global Solutions for Urban Drainage, ed, 2002, pp. 1-16.

50. J. Mullaney, P. Rikalainen, and C. Jefferies, "Pollution profiling and particle size distribution within permeable paving units-with and without a geotextile," Management of Environmental Quality: An International Journal,23, pp. 150-162, 2012. 